\title{
ИДЕНТИЧНОСТЬ И САМОПРЕЗЕНТАЦИЯ ЛИЧНОСТИ В ЦИФРОВЫХ МЕДИА. О КН.: ЛИСЕНКОВА А.А. ТРАНСФОРМАЦИЯ СОЦИОКУЛЬТУРНОЙ ИДЕНТИЧНОСТИ В ЦИФРОВОМ ПРОСТРАНСТВЕ: МОНОГРАФИЯ. ПЕРМЬ: ПЕРМСКИЙ ГОСУДАРСТВЕННЫЙ ИНСТИТУТ КУЛЬТУРЫ, 2021. 286 c.
}

\begin{abstract}
Рецензия посвящена монографии, в которой осмысливается сочииально-культурныле эффекты развития циифровых технологий в современном обществе, в частности степень их влияния на прочессы идентификации и социализации. Автор рецензии отмечает, что особое внимание в данном издании уделено формированию сочиокультурной идентичности российской молодежи в пространстве новых медиа (в том числе сочиильных сетей), стратегиям и практикам репрезентаџии, формам публичной нарративизаџии и визуализацчи повседневного опьтта. Виртуальная циирровая среда представлена в виде комплексного феномена, пронизывающего все сферы жизни человека, формирующего новые требования к его компетенциям, знаниям, умениям и навыкам, создающего не только интерактивное пространство взаимодействия, но и порождающего риски и угрозы нового порядка. Рецензируемая монография адресована широкому кругу читателей, включая культурологов, философов, специиалистов по социальной и культурной антропологии, преподавателей и студентов гуманитарных вузов, всех кому интересны современные культурные процессы и различные аспекты развития циифрового общества.
\end{abstract}

Ключевые слова: идентичность, виртуализация, самопрезентащия, молодежь, цифрровизачия, новье медиа, репрезентаџия, сочиализация, социальные сети, нарратив

Ссылка при цитировании: Тульчинский Г.Л. Идентичность и самопрезентация личности в цифровых медиа. О кн.: Лисенкова А.А. Трансформация социокультурной идентичности в цифровом пространстве: Монография. Пермь: Пермский государственный институт культуры, 2021. // Вестник антропологии, 2021. № 3. С. 320-326.

Тульчинский Григорий Львович - д. философ. н., профессор, Национальный исследовательский университет «Высшая школа экономики» (190121 Санкт-Петербург, Союза Печатников ул., д.16). Эл. почта: gtul@mail.ru 
Если еще не так давно медиа транслировали некие социальные значения осмысленной информации, выступающие гарантиями взаимопонимания и консолидации, то современные медийные технологии, резко увеличившие доступность, масштаб и скорость коммуникации, сместили акцент на личностные смыслы - оценки, эмоции и переживания, зачастую без всякой рефлексии, непосредственно представляемые в коммуникативном пространстве. Интернет, социальные сети переполнены этим личностным контентом, а его со все большей скоростью нарастающий объем ставит серьезные проблемы (социальные и каждого из нас) выбора, ограничения, выработки критериев фильтрации этого потока.

Личностное измерение бытия - одна из ключевых характеристик современной картины действительности. Если философия еще начала XX в. преимущественно задавалась вопросами о природе сущего, истины как гарантии познания сущего, то в последующие десятилетия на первый план последовательно выходили вопросы о зависимости познания от способов (методов) познания, от культуральных (ценностно-нормативных) факторов и контекстов, определяющих методологию и - к личности как как источнику, средству и результату динамики осмысления и смыслообразования. Этот персонологический сдвиг гуманитарной парадигмы закрепился в когнитивных исследованиях, нейропсихологии, нейрофизиологии мозга. Так что характер современной коммуникации - одно из выражений этой глубокой тенденции.

Интерес к проблеме идентичности как формирования, презентации и позиционирования самосознания (самости, «яйности») - не дань моде, а следование векторам осмысления современной реальности, сходящимся на этой проблеме.

Под социально-культурной идентичностью автор рецензируемой книги понимает самоотождествление индивида с какими-либо культурами, что позволяет личности в наиболее полной мере осознать и принять свою социально-ценностную и эмоционально-психологическую принадлежность и значимость как члена определенной общности. Такой подход, с одной стороны, позволяет конкретизировать социально-культурную идентичность как комплекс гражданской, этнической, гендерной, возрастной, политической, профессиональной, досуговой и ряда других идентичностей. С другой стороны, он ставит ряд вопросов концептуального характера, прежде всего - относительно факторов формирования такой идентичности. Например, в какой степени оно зависит от признания сообществом - его, так сказать, внешней идентификации другими. Или - как соотносятся осознание принадлежности сообществу и позиционирование личностью себя в данном сообществе и вне его, в публичной и не публичной коммуникации. Наконец, какую роль в этих процессах играют способы и каналы коммуникации.

Сетевые коммуникации, размывая культурные границы и нормы ведут к вытеснению значимости таких традиционных характеристик личности как возраст, раса, пол и т.п.), выводя на первый план новые категории социального персонального опыта, формируемые цифровой средой. В стремлении к самоопределению человек стал соотносить себя не только с аналогичными, близкими взглядами и оценками, но и противопоставлять собственные оценки, взгляды и интересы другим, включая себя в виртуальный социум не только на основе сопричастности, но и противопоставления.

Поэтому в анализе социально-культурной идентичности, особенно в современных условиях, очень многое зависит от фокусировки исследователя в этом обширном проблемном поле. С этой задачей А.А. Лисенкова справляется довольно успешно, реализовав, фактически три приближения такой фокусировки. Во-первых, в качестве предмета 
рассмотрения была выбрана динамика социально-культурной идентичности в электронных социальных сетях, открывших новые возможности не только позиционированию личности в современном социуме, но и придавших самому социуму дополнительную пластичность. Можно признать, что социальные сети в современном мире предстают одним из существенных факторов культурогенеза, расширяя поле социально-культурных практик, социализации и индивидуализации. Во-вторых, в качестве основного актора в таких практиках автором небезосновательно выбрана молодежь - наиболее открытая изменениям часть общества, нередко выступающая проводником и бенефициаром этих изменений, определяя, тем самым, тренды и перспективы развития. При этом показательно, что эту наиболее активную часть пользователей социальных сетей фактически никто не обучает сетевой грамотности и критическому цифровому анализу - молодые люди всему этому обучаются на собственном опыте и опыте своих сверстников. В этом плане молодежь всегда была и остается самым благодатным материалом для выявления и осмысления тенденций развития. И, в-третьих, А.А. Лисенкова делает особый акцент на специфике и роли визуальных практик сетевых коммуникаций - эти практики во все большей степени выходят на первый план как в цифровых технологиях, так в интересе пользователей этими технологиями. Визуализация серьезно теснит вербально-текстовую презентацию и трансляцию информации.

Первая глава книги посвящена осмыслению самого феномена социально-культурной (социокультурной, как предпочитает выражаться автор) идентичности в новой цифровой реальности. Со времен 3. Фрейда идентичность - как форма адаптации индивида к социальной среде - имеет богатейшую литературу. В настоящее время идентичность все более и более обретает характер формирования и продвижения некоего проекта личности, в котором активную роль играет как сама личность, так и ее социальная среда, а этничность, статус, социальные роли становятся не целью, конечным результатом позиционирования, а средством реализации проекта. По мнению автора книги, в этом процессе решающую роль играют нарративы и визуализация как ключевые средства осмысления места и значения индивида в социуме. При этом важно, что дело не ограничивается когнитивными и эмоциональными характеристиками процесса - принципиально важно проявление идентичности в поведении и поступках.

Начав с анализа теоретических подходов к изучению самого феномена идентичности и отдав дань особенностям формирования непростой современной российской социокультурной идентичности, автор переходит к рассмотрению цифровизации, как фактора трансформации идентификационных процессов. В этом контексте идентичность, по мнению автора предстает как «накопленный индивидуальный опыт, присвоенный воображением и «переведенный» им в образный контекст конкретной культуры», а глобальная цифровая коммуникативная среда - «практически чистым полем эксперимента, ... поскольку, с одной стороны, является пространством возможностей преодоления анонимности, а с другой - социально сформированным полем, в котором сложилась и действует своя мифология, позволяющая идентифицировать себя различными способами» (с. 34-35). Выявленный автором круг мотивации молодых людей к активной онлайн-коммуникации широк: поиск чувства защищенности, сопричастности; конструирование идеального образа себя; тестирование ролей взрослых; трансляция социально-одобряемого поведения; развлечение; желание публично поделиться тайной, часто анонимно; поиск поддержки; обучение; создание «личной истории», визуализации успеха. (с.66-67). Обобщение 
представленного материала позволяет завершить главу формулировкой основания реализации цифровой идентификации. Такое основание - «модульный принцип» автор связывает с виртуализацией и интерактивностью презентации, восприятия и продвижения информации в современной коммуникации. Имеются ввиду возможности различных сетевых платформ для позиционирования личности и перехода таких самопрезентаций из виртуального пространства в «реальное» и наоборот. Реальное я сознательно беру в кавычки, потому что виртуальное пространство не менее реально, чем привычное - и в том, и в другом случаях задействованы естественные процессы их формирования и восприятия. В этом плане «виртуальное» выступает просто расширением, еще одним измерением реального. Именно это и обеспечивает «самопроектной» идентичности онлайн невиданные ранее возможности, когда человек может добиться самореализации, социального признания, паблицитного капитала, финансового благополучия - не выходя офлайн. И это - с одной стороны. А с другой - и автор потом разделяет эту точку зрения (с 120-121), культурные практики, как и культура в целом, могут рассматриваться как «виртуальная реальность», возникающая и транслируемая в социальной коммуникации.

Во второй главе детально рассматриваются новые медиа - как средство реализации интерпретаций и новых практик идентификации личности, включая развитие новых медиа от Web 1.0 к Web 4.0, особенности проектной идентификации в этих форматах, визуализации желаемого. Завершается глава типологией медийной презентации идентичности. Так, в рамках реализации определенных стратегий сетевого присутствия автор различает «модульную идентичность», предъявляемую в качестве фрагмента в зависимости от обстоятельств, а также «проектную идентичность», формируемую и продвигаемую в сетях, стихийно или сознательно - по всем правилам маркетинга и брендинга. Как реакция на поток сетевой информации в комментариях, троллинге может проявляться «спонтанно-рефлексивный» тип идентичности. Это могут быть проявления, претензии или подтверждения «статусно-ролевой идентичности» - в рамках производственной или также досуговой деятельности - как офлайн, так и сугубо онлайн. В последнем случае это может быть результатом развития «релевантной идентичности», обусловленной постоянной включенностью в сетевое общение, как это происходит в блогосфере с накоплением фолловеров и подписчиков. Неустойчивость, трансформации внешнего мира и представлений о самом себе порождают «диффузную идентичность». В погоне за признанием, востребованностью и утверждением собственной значимости иногда реализуется практика «мнимых идентичностей», чреватая ловушкой психологических девиаций, а то и конфликтов с законом.

Все эти возможности конструирования и обретения идентичности - вне зависимости от степени их осознанности - влияют не только на формирование личности, но и на развитие общества в целом, провоцируют новые формы неравенства, сегрегации, конфликтов. При этом, в отличие от доинформационного общества, эти типы сетевой идентичности по своей сути перформативны, они постоянно подтверждаются и верифицируются в сетевой коммуникации.

Проведенный анализ и предварительная систематизация позволили перейти в третьей главе к рассмотрению нарративных практик публичной виртуализации персонального опыта в медийной среде. При этом автор обращается к презентации в этой среде опыта основных акторов виртуального пространства - молодежи и детей, большую часть времени проводящих в сети и не делающих различия между жизнью в сети 
и вне ее. Для них именно Интернет - главный источник информации и опыта, а постоянные, даже непрерывные рассказы о своих впечатлениях, событиях, отношениях, успехах становятся нарративной практикой не только самопозиционирования, но и в процессе такого позиционирования - конструированием собственной идентичности.

Специальное внимание автором уделяется влиянию медиа-среды на формирование ценностных установок современной городской молодежи, особенностям социализации «детей цифрового мира», включая сетевой поиск «своих» («самокатегоризацию» и «народную таксономию»). Автору удалось выявить наиболее популярные молодежные группы и паблики в основных социальных сетях (ВКонтакте, Одноклассники, Instagram, TikTok). Анализ их контента показывает, что количество «друзей», лайков и репостов в сети превращает аккаунты в «проекции желаемого Я», демонстрации «себя успешного». Такой анализ видится особенно важным - коммуникация в цифровых форматах, несмотря на все ее достоинства, лишает многогранности и сложности человеческих взаимоотношений, во многом обезличивает общение, но одновременно создает условия для саморазвития, развлечения, приобретения различного опыта - вплоть до манипулирования. Как отмечает автор, сегодня более 70\% школьников сталкиваются с предложениями «дружить» от совершенно незнакомых людей и $23 \%$ сталкивались с проявлением кибербуллинга.

В четвертой главе горизонты рассмотрения расширяются - рассматриваются последствия сетевого позиционирования личности, вплоть до формирования ценностно-нормативного содержания нового культурогенеза: мифология и героизация в виртуальном сетевом мире, доверие и манипулирование, агрессия онлайн, их продолжение в реальном мире офлайн. Автор подчеркивает, что отличительной характерной особенностью новых мифов в условиях развития цифровых технологий стали «сенсация и гипертрофированность с повышенной истерией» (с.169), что сказывается на общей смысловой картине реальности, проявляясь в феноменах фейков и пост-правды. Современность породила массы отчужденных людей, транслирующих в сеть бесконечные персональные наррации, и для того, чтобы выделиться в этом потоке, стать известным и узнаваемым персонажем не всегда нужны добродетель и доблесть. В погоне за лайками, репостами, быстрой славой (хайпом) человек стал выставлять на публичное обозрение и обсуждение приватно-интимное, а повышенный до скандальности эмоциональный фон обеспечивают привлечение внимания. И отрицательный хайп, ажиотаж вокруг девиаций становятся источником не меньшей популярности и дохода, чем позитивно-конструктивный успех. Героям современных медиа свойственны: размытость ценностных ориентаций, границ публичного и приватного; гипертрофированная эмоциональность, перформативность персонального опыта; желание быть признанным и популярным «любой ценой», капитализировать популярность.

Обилие информации и интенсивность коммуникации создают не только предпосылки открытости, общественного контроля, гражданского участия. Неоднократно отмечалось и данное исследование это подтверждает, что социальные сети не способствуют росту доверия и консолидации. Вроде бы сформировались самодостаточные сетевые сообщества, члены которого лайкают друг друга и достаточно недоверчиво и агрессивно настроены по отношению к другим. Однако из проведенного автором опроса следует, что друзьям и информации от друзей (даже несмотря на то, что со многими из них пользователи знакомы лично) респонденты доверяют в меньшей степени, чем сообщениям от посторонних мало знакомых людей. Мнению специа- 
листов в какой-либо отрасли доверяют значительно больше $(83,93 \%)$, чем мнению друзей (7,14\%). Пользователи сетей имеют обычно большое количество «друзей» (до 100 человек - 20,37\%, 100-200 человек - 29,63\%, 200-300 человек - 22,22\%, 300-400 $11,1 \%$ ), но лично знакомы и общаются в реальной жизни из них $52,7 \%$ менее, чем с 50 «друзьями», 23,1\% 50-100 - «друзьями» и лишь 17,5\% знакомо лично более, чем со 100 «друзьями» из социальных сетей. Другими словами, социальные сети мало способствуют даже росту «сплачивающего доверия, не говоря уже о доверии «наводящем мосты». Имеет место некое гипертрофированное возбуждение онлайн, не часто ведущее к сотрудничеству и партнерству офлайн. Более того, социальные сети выступили средой эмоциональных выбросов, рессентимента, реализации возможных девиаций, питательной средой агрессивных настроений и проявлений агрессии. Сетевая агрессия в формах троллинга, пранкерства, кибербуллинга, флуда, хейтерства, астротурфинга, флейминга - создают деструктивный фон не только для сетевого взаимодействия. Истеричность и агрессивность в социальных сетях и традиционных медиа дополняют и усиливает друг друга, сказываясь на социализации и самоопределении личности.

Пятая глава завершает исследование выявлением и систематизацией возможностей, вызовов и рисков, возникающих в контексте цифровых медийных коммуникаций для социализации личности и для общества, требований к цифровой коммуникативной компетентности, предъявляемых к современному человеку, а также формированию экологии виртуального коммуникативного пространства. Намечены векторы необходимого дальнейшего анализа.

Завершают монографию приложения, включающие словарь терминов по теме работы (62 специальных термина), библиографию (251 источник), также ссылки на электронные ресурсы с авторскими анкетами и их аналитикой.

К сожалению, за рамками концептуального анализа осталось различение идентичности как выражения рефлексивного самосознания, самоопределения личности по отношению к социально-культурной среде, и идентификации - как формы позиционирования личности в социуме на основе внешних оценок ее характеристик. Такое различение представляется главным нервом проблемы. И оно открывало бы больше возможностей для систематизации способов позиционирования личности в социуме как самой личностью, так и внешними акторами, интерактивного взаимодействия с ними самого индивида. Не случайно автор, характеризуя контент личных профилей в социальных сетях, говорит о нем то как об идентичности, то как о идентификационной стратегии. Без отмеченных важных уточнений несколько «провисают» некоторые рассуждения и утверждения относительно «репрезентации подлинной идентичности», «латентной идентичности», «репрезентации идеального желаемого» и «виртуальных игр с идентичностью» (с.45). А это важно - тем более, что и сама автор подчеркивает, что в условиях цифровизации «виртуальные форматы бытования собственного «Я»... становятся все более явными и публичными» и даже «принудительно публичными за счет включенности в цифровой мир» (там же), в котором речь идет не о возможности «спрятаться», а именно об отнесении личности к конкретным категориям и алгоритмизации обработки этих данных в целях контроля. Да и результаты проведенного автором масштабного опроса подтверждают сращивание реальной жизни и виртуальных профилей. 78,4\% опрошенных полагают, что по их профилю в социальной сети можно судить об их взглядах и увлечениях, а $84 \%$ согласны с тем, что эта информация адекватно представляет их интересы и мировоззрение (с.116). 
Означает ли это, что идентичность, как самосознание «от первого лица» переходит в идентификацию, как характеристику самости «от третьего лица»? Последняя моделируется в искусственных системах, моделируема и воспроизводима. Однако похоже, что главное, что выделяет человека среди других живых и искусственных существ - не просто феномен сознания, а именно наличие самосознания - субъективности «в первом лице», уникального телесного опыта и эмоционально окрашенных переживаний, их рефлексии. Но это уже другая тема.

Подводя итог даже столь беглого знакомство с содержанием книги А.А. Лисенковой необходимо признать, что представленное в ней исследование выгодно отличается от нередких текстов, в которых авторы-гуманитарии делятся радостью узнавания новых технологий социальной коммуникации или предаются алармическим рефлексиям (иногда преходящим в хорроризацию читателей и самих себя) относительно последствий их развития. Рецензируемая книга являет собой успешный пример реализации масштабной социально-культурной экспертизы важного кластера современной социальной жизни - позиционирования личности, находящейся в активной стадии социальной индивидуализации с помощью цифровых медиа: выявлены факторы, рассмотрены технологии, прослежены механизмы и процессы, выявлены неоднозначные последствия и сформулированы требования, необходимые для оптимизации вхождения молодого поколения в социально-культурную жизнь современного социума.

Tulchinsky, G.L.

\section{Identity And Self-Presentation In Digital Media. Book Review: Lisenkova A. Transfor- mation Of Socio-Cultural Identity In The Digital Space. Perm, 2021}

DOI: $10.33876 / 2311-0546 / 2021-3 / 320-326$

The review is devoted to the monograph, which comprehends the socio-cultural effects of the development of digital technologies in modern society, in particular, the degree of their influence on the processes of identification and socialization. The author of the review notes that special attention in this publication is paid to the formation of the socio-cultural identity of Russian youth in the space of new media (including social networks), strategies and practices of representation, forms of public narrativization and visualization of everyday experience. The virtual digital environment is presented as a complex phenomenon that permeates all spheres of human life, forming new requirements for his competencies, knowledge, skills and abilities, creating not only an interactive interaction space, but also generating risks and threats of a new order. The reviewed monograph is addressed to a wide range of readers, including cultural scientists, philosophers, specialists in social and cultural anthropology, teachers and students of humanities universities, all who are interested in modern cultural processes and various aspects of the development of a digital society.

Keywords: Identity, Virtualization, Self-presentation, Youth, Digitalization, New media, Representation, Socialization, Social networks, Narrative

For Citation: Tulchinsky, G.L. 2021. Identity and Self-presentation of the Individual in Digital Media. About the book by A. Lisenkova "Transformation of socio-cultural identity in the digital space", Perm, 2021. Herald of Anthropology (Vestnik Antropologii) 3: 320-326.

Author Info: Tulchinsky, Grigory L. - Dr. (Philosophy), Professor, Higher School of Economics University (190121 St. Petersburg, RF). E-mail: gtul@mail.ru 